\title{
Therapeutic Patient Education
}

\section{Annice Heratizadeh, MD}

\author{
Address \\ Division of Immunodermatology and Allergy Research, Department of Dermatol- \\ ogy and Allergy, Hannover Medical School, Carl-Neuberg Str. 1, 30625, Hannover, \\ Germany \\ Email: Heratizadeh.Annice@mh-hannover.de
}

Published online: 18 September 2014

(C) Springer International Publishing AG 2014

Keywords Atopic dermatitis - Therapeutic patient education - Educational program - Disease severity - Quality of life

\section{Opinion statement}

Patient education in atopic dermatitis (AD) represents an essential therapeutic tool, which should be offered in addition to routine care, since previous studies have revealed that $A D$ outpatients are often insufficiently treated and show severe limitations of quality of life. Considering the multifactorial pathogenesis of this chronic skin disease, the success of therapeutic patient education seems to depend on the involvement of a multidisciplinary team of professionals. The training program should include aspects on dermatology and allergy, but also on diet and nursing, as well as on disease-specific psychological issues. Synergistic beneficial effects upon interaction between affected patients or parents should be considered by performing the training in small groups. The overall aim of therapeutic patient education in $A D$ should be an improvement of selfmanagement strategies to finally achieve a decrease in disease severity and an increase in quality of life. For children (and their parents) and adolescents with $A D$, successful programs have already been developed. However, in many countries, there is still a need for official recommendations in order to regulate reimbursement for the costs of such programs. Since the preliminary results from pilot studies in adults have been promising, further large controlled trials on patient education in this age group are needed to finally improve outpatient care also in adulthood AD.

\section{Introduction}

Atopic dermatitis (AD) is a chronic inflammatory skin disease, affecting up to $20 \%$ of children and $1-3 \%$ of adults in Western industrialized countries. At every age, the course of the disease can be characterized by exacerbations and remissions. In particular, during periods of high disease activity, continuous medical care is indicated. Educational programs aim to improve the quality of life of affected children and adolescents and their parents, as well as that of affected adults $[1 \bullet]$. Compared with the number of controlled studies on medical therapy in AD, only a few controlled trials on the effects of training programs have been performed so far. Nevertheless, because of the convincing beneficial effects, international experts on $\mathrm{AD}$ have argued for integration of educational programs into the therapeutic regimen. Moreover, educational 
intervention has been included in the recommendations of the European guideline for treatment of $\mathrm{AD}[2]$.
Here, an overview is provided on the status quo regarding the results of educational programs, in particular for outpatients with AD.

\section{Why are educational programs for AD patients necessary?}

For optimal treatment, the therapeutic regimen should not only be in accordance with the patient's history and diagnostic results but should also consider the patient's experience of previous therapeutic interventions. This, in turn, necessitates a complete and often time-consuming assessment of relevant patient-specific information by specialized personnel. Moreover, the complex and multifactorial pathogenesis of $\mathrm{AD}$ [3] represents a challenge for both the physician and the patient. On the one hand, this implies that in many cases, patient care by an interdisciplinary team-considering medical as well as dietary or psychological aspects, for example-is advisable. On the other hand, the patients or their parents can be requested to perform a variety of therapeutic interventions. But, for organizational reasons in routine care, they often cannot be adequately instructed or informed about the ratio of beneficial effects and possible side effects of certain medications, such as corticosteroids.

Although a variety of modern preparations of topical corticosteroids is available, a high percentage of patients with $\mathrm{AD}$ still show fear of corticosteroids, also contributing to poor adherence [4]. Previous studies on patientcentered care focusing on the outpatient situation close to the patients' homes revealed that in this setting, AD patients are mostly insufficiently treated [5] and show more severe limitations of quality of life than those observed in many other chronic skin diseases [6, 7]. Insufficient therapy may finally result in a reduction in therapeutic adherence. Without being supervised by a specialist, patients tend to randomly undertake multiple therapeutic attempts. In fact, AD patients frequently use alternative medicine [8], although these approaches lack sufficient evidence of efficacy [9] and are-from the patients' perspective-rated lowest compared with the benefit of conventional interventions [10]. Moreover, use of complementary therapy, such as homoeopathic therapy in children with $\mathrm{AD}$, is associated with higher costs, although the effects are not superior to those of conventional treatments [11]. Regarding the economic impact of the disease, an increase in disease-related costs with the severity of the disease can be observed $[12,13]$. In Germany, total yearly costs of $€ 1,425$ per patient have been calculated, resulting in costs of $€ 1.6-3.6$ billion per year in society as a whole. Diseaserelated costs also directly affect the patients themselves or their parents. Regarding the behavior of the affected patients from the economic point of view, in particular, patients with $\mathrm{AD}$ are characterized by a moderate-to-high willingness to pay, as has been shown in a nationwide German study [7].

These data and the results from the studies available so far (see below) support the concept that to optimize disease management in $\mathrm{AD}$, an effective 
transfer of knowledge from specialists in different disciplines to the patients (or parents) is essential. The following criteria of educational programs seem to be most relevant: (1) they should be offered to all affected patients (families), irrespective of their socioeconomic status; (2) they should be conducted by a multidisciplinary team of professionals; and (3) they should be performed in (age-related) small groups.

\section{Educational training programs for children (or their parents) and adolescents}

Most controlled studies on educational programs for children and adolescents have primarily focused on their effects on quality of life $[1 \bullet]$.

In a parallel-group study, Chinn et al. included families of children aged $<4$ years $(n=115)$, as well as children and adolescents aged 4-16 years $(n=120)$, who were instructed by a dermatology nurse during a single 30-minute session [14]. Since no significant effects on quality-oflife parameters were observable after 4 weeks nor after 12 weeks of follow-up, the authors concluded that the study population should have been larger and the disease activity higher; therefore, they proposed using additional outcome measures.

So did Shaw et al., who defined disease severity as a further outcome measure (the SCORAD [SCORing Atopic Dermatitis] index) [15]. The study population ( $n=106$, aged $0-18$ years) showed quite high disease activity, with a mean SCORAD score of $\geq 50$ at baseline. Again, the intervention was a single (15-minute) session, conducted by a senior medical student. However, the educational intervention did not reveal any significant effects, compared with the control group. The authors discussed several reasons for this outcome. First, it might have been due to a high dropout rate (30\%). Second, the outcome was probably also negatively influenced by the fact that some caregivers were trained who did not primarily care for the child. Finally, individuals in the control group were receiving advice from pediatric and dermatological specialists during their routine appointments.

Grillo et al. extended the duration of the educational intervention and performed a 2-hour workshop [16]. Information on the staff conducting the workshop was not provided. In this study population, the mean disease activity of $\mathrm{AD}$ was also severe, with a baseline SCORAD score of $\geq 47$. Although only 58 patients (aged 0 months to 16 years) were included, 4-week and 12-week follow-up assessments both showed a significant decrease in disease severity (the SCORAD score), compared with the control group, while quality-of-life parameters did not improve.

It is well established that particularly in chronically relapsing cases, the daily life of the children and their families is severely affected by the disease-not just over a period of weeks but mostly over several months or even years. The studies cited above defined "quality of life" as a primary outcome measure. However, the content of the training sessions predominantly focused on disease-specific information in dermatology, including nursing aspects, while disease-specific psychological issues, combined with advice on successful coping strategies, were left out. 
Considering established training programs for other diseases in childhood, such as asthma [17], Staab et al. performed a large $(n=823)$ German multicenter randomized controlled trial on the effect of a structured educational program in children and adolescents with AD (aged 0-18 years) [18]. The training concept was more comprehensive, since the training sessions were performed once weekly for 2 hours over a period of 6 weeks. In order to empower the parents and patients in all relevant fields of the disease, training sessions were conducted by an interdisciplinary professional team of specialists (pediatricians, dermatologists, psychologists, and dieticians), who had previously attained a study-specific qualification. The content of each session was standardized and binding, since a training manual had been drafted. Furthermore, parents or patients were educated in small, age-related groups. The 12month follow-up visit showed a significant improvement in $\mathrm{AD}$ (the SCORAD score) in all intervention groups. Moreover, in parents of children aged $<7$ years, all quality-of-life subscale scores were significantly ameliorated, and in parents of children aged 8-12 years, a significant improvement in 3 out of 5 subscales was observable as well. Furthermore, a greater improvement in children's coping behavior and in parents' handling of their children was observable [19]. Quality of life in children (aged 8-12 years) and adolescents (aged 13-18 years) showed a significant negative correlation with itch intensity [20]. Weber et al. also analyzed the effects on itch [21] by joining support groups. Meetings for children (lasting 90 minutes, fortnightly over 6 months) were coordinated by a child psychiatrist together with a volunteer medical student. The sessions included playing, drawing, simulations, and performances. The meetings for parents, coordinated by a senior dermatologist with two other dermatologists, were mainly for explaining and discussing different subjects. The total study population was small, with 16 patients each in the intervention group and in the control group. The authors observed an improvement in the pattern, but not the intensity, of pruritus, as well as a significant improvement in quality of life. One aspect that this program and the program established by Staab et al. [18] had in common was that the meetings were organized in small groups. In this setting, helpful communication between the participants was made possible, and they, in turn, could also provide encouragement to each other. This assumption is supported by data analysis from 73 parents, elucidating that low social support but high active problem-solving behavior are characteristics of those parents who are interested in participating in educational programs [22].

In summary, the data available on patient education for infants and children (and their parents) and adolescents with AD clearly indicate that for educational programs to be successful, it is essential that they consider the multifactorial disease concept.

After the data from the German multicenter study was published in 2006, head associations of German insurance companies recommended in 2007 that the costs of such educational programs be reimbursed by regional health insurance. Since then, participation in such programs has involved German health insurance in most cases. Remarkably, this is in contrast to the international situation. Recently, Stalder et al. offered an 
overview on worldwide experiences of therapeutic patient education in $\mathrm{AD}[23 \bullet \bullet]$. While in France, funding comes from regional health authorities, it comes from donations in the USA and from pharmaceutical

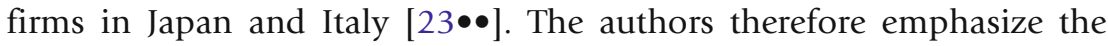
need for official validated recommendations in AD programs.

\section{Educational training programs for adult patients}

Although approximately $30 \%$ of those who have suffered from AD in childhood still have AD symptoms in adulthood, the data available on disease-specific educational programs are sparse. In their international overview of experiences in therapeutic patient education, Stalder et al. determined that patients in these programs were mainly children and adolescents $[23 \bullet \bullet]$.

Although most affected adult patients have much experience of different therapeutic approaches, their knowledge of the pathogenesis of $\mathrm{AD}$ and evidence-based treatment options is often incomplete. Indeed, Dagregorio and Guillet reported that $48 \%$ of $\mathrm{AD}$ patients attending an educational seminar thought that asthma could be triggered or aggravated by successful therapy for $\mathrm{AD}$ [24].

In 1995, Ehlers et al. performed the first randomized controlled study on an educational intervention, including 135 patients [25]. Effects in four different treatment groups were assessed: (1) dermatological education; (2) autogenic training; (3) cognitive-behavioral therapy; and (4)a combination of dermatological education and cognitive-behavioral therapy. The effects were also compared with observations in a control group receiving standard medical care. Since psychological interventions led to a significantly greater improvement in $\mathrm{AD}$ than dermatological education alone or treatment by routine care, the outcome of this study implied a vital need for psychological issues to also be addressed in educational programs for adults.

In Great Britain, educational intervention is mostly performed by a nurse. In a controlled trial, a practice nurse, who had received training in practical dermatology care, trained adult patients [26]. Although the training was offered as often as needed over a period of 4 months, no significant improvement in the intervention group $(n=46)$, compared with the control group $(n=54)$, was achieved. In this context, data from Gradwell et al. are worth noting, since they assessed the effects of providing a nurse follow-up clinic in addition to routine care by a dermatology outpatient department [27]. Because there was a significant increase in knowledge on how to apply the treatment and how to obtain disease-specific care, the authors finally stated that support from dermatology nurses can indeed be beneficial.

In a Dutch pilot study on a multidisciplinary program, nursing aspects were also part of the educational concept. Coenraads et al. performed a trial in $51 \mathrm{AD}$ patients (aged 18-35 years) [28]. Small training groups of five patients received educational training from a multidisciplinary team, consisting of dermatological education and also including information on the pathogenesis of $\mathrm{AD}$, dietary education, nursing aspects, and the psychosocial aspect. The duration of the program was 6 hours over a period of 10 days. This educational program revealed a significant improvement in coping strategies and disease management. Regarding the economic effects, the time needed for visits to doctors and days of inability to work were significantly reduced as well. 
In a recent parallel-group study from Belgium, the intervention group ( $\mathrm{n}=$ 21) participated in a 12-week educational program ( 2 hours twice a week) given by a multidisciplinary team [29]. Despite a broad variety of issues being discussed with the patients during the lessons, no significant effects at 3 months were observable. It should be emphasized that AD patients were educated together with psoriasis patients, who did show improvements in their quality of life and skin conditions after being educated. It can be speculated that in this setting, relevant AD-specific aspects—such as pruritus and sleeplessness, for example-were neglected.

In 2010, the ARNE Study Group-consisting of a nationwide multidisciplinary team of professionals in dermatology, psychology, psychosomatics and psychotherapy, medical sociology, dietary science, ecotrophology, and health services research-initiated a German multicenter study on a new educational outpatient program for adults, with a 1-year follow-up period [30]. The first results from this trial are expected at the end of 2014.

So far, the evidence of beneficial effects of educational programs in adult $\mathrm{AD}$ patients is insufficient. As a consequence, reimbursement for the costs of participation in outpatient educational programs on $\mathrm{AD}$ seems to be unregulated. In Germany, health insurance companies pay for therapeutic outpatient education on $\mathrm{AD}$ in selected cases, but most applications are denied. This is in contrast to the inpatient situation in rehabilitation departments. In conclusion, further large randomized controlled studies on educational programs are needed, which should primarily aim to promote self-disease management capacity and improve the coping strategies of adult outpatients suffering from $\mathrm{AD}$.

\section{Compliance with Ethics Guidelines}

Conflict of Interest

Annice Heratizadeh declares no conflict of interest.

Human and Animal Rights and Informed Consent

This article does not contain any studies with human or animal subjects performed by the author.

\section{References and Recommended Reading}

Papers of particular interest, published recently, have been highlighted as:

- Of importance

-• Of major importance

1.• de Bes J, Legierse CM, Prinsen CA, de Korte J. Patient education in chronic skin diseases: a systematic review. Acta Derm Venereol. 2011;91(1):12-7.

Systematic review focusing on the effects of patient education on quality of life and disease severity, particularly in patients with atopic dermatitis

2. Ring J, Alomar A, Bieber T, Deleuran M, Fink-Wagner A, Gelmetti C, et al. Guidelines for treatment of atopic eczema (atopic dermatitis) part II. J Eur Acad Dermatol Venereol. 2012;26(9):1176-93.
3. Werfel T, Claes C, Kulp W, Greiner W, von der Schulenburg JM. Therapy of atopic eczema. GMS Health Technol Assess. 2006;2:Doc19.

4. Aubert-Wastiaux H, Moret L, Le Rhun A, Fontenoy AM, Nguyen JM, Leux C, et al. Topical corticosteroid phobia in atopic dermatitis: a study of its nature, origins and frequency. Br J Dermatol. 2011;165(4):808-14.

5. Zuberbier T, Orlow SJ, Paller AS, Taieb A, Allen R, Hernanz-Hermosa JM, et al. Patient perspectives on the 
management of atopic dermatitis. J Allergy Clin Immunol. 2006;118(1):226-32.

6. Schmid-Ott G, Burchard R, Niederauer HH, Lamprecht F, Kunsebeck HW. Stigmatization and quality of life of patients with psoriasis and atopic dermatitis [in German]. Hautarzt. 2003;54(9):852-7.

7. Beikert FC, Langenbruch AK, Radtke MA, Kornek T, Purwins S, Augustin M. Willingness to pay and quality of life in patients with atopic dermatitis. Arch Dermatol Res. 2014;306(3):279-86.

8. Hughes R, Ward D, Tobin AM, Keegan K, Kirby B. The use of alternative medicine in pediatric patients with atopic dermatitis. Pediatr Dermatol. 2007;24(2):118-20.

9. Torley D, Futamura M, Williams HC, Thomas KS. What's new in atopic eczema? An analysis of systematic reviews published in 2010-11. Clin Exp Dermatol. 2013;38(5):449-56.

10. Steinke S, Langenbruch A, Ständer S, Franzke N, Augustin M. Therapeutic benefits in atopic dermatitis care from the patients' perspective: results of the German national health care study 'Atopic Health'. Dermatology. 2014;228(4):350-9.

11. Roll S, Reinhold T, Pach D, Brinkhaus B, Icke K, Staab $\mathrm{D}$, et al. Comparative effectiveness of homoeopathic vs. conventional therapy in usual care of atopic eczema in children: long-term medical and economic outcomes. PLoS One. 2013;8(1):e54973.

12. Ehlken B, Mohrenschlager M, Kugland B, Berger K, Quednau K, Ring J. Cost-of-illness study in patients suffering from atopic eczema in Germany [in German]. Hautarzt. 2005;56(12):1144-51.

13. Werfel T, Aberer W, Augustin M, Biedermann T, FolsterHolst R, Friedrichs F, et al. Atopic dermatitis: S2 guidelines [in German]. J Dtsch Dermatol Ges. 2009;7 Suppl 1:S1-46.

14. Chinn DJ, Poyner T, Sibley G. Randomized controlled trial of a single dermatology nurse consultation in primary care on the quality of life of children with atopic eczema. Br J Dermatol. 2002;146(3):432-9.

15. Shaw M, Morrell DS, Goldsmith LA. A study of targeted enhanced patient care for pediatric atopic dermatitis (STEP PAD). Pediatr Dermatol. 2008;25(1):19-24.

16. Grillo M, Gassner L, Marshman G, Dunn S, Hudson P. Pediatric atopic eczema: the impact of an educational intervention. Pediatr Dermatol. 2006;23(5):428-36.

17. Gebert N, Hummelink R, Konning J, Staab D, Schmidt S, Szczepanski R, et al. Efficacy of a self-management program for childhood asthma-a prospective controlled study. Patient Educ Couns. 1998;35(3):213-20.

18. Staab D, Diepgen TL, Fartasch M, Kupfer J, LobCorzilius T, Ring J, et al. Age related, structured educational programmes for the management of atopic dermatitis in children and adolescents: multicentre, randomised controlled trial. BMJ.

2006;332(7547):933-8.
19. Kupfer J, Gieler U, Diepgen TL, Fartasch M, LobCorzilius T, Ring J, et al. Structured education program improves the coping with atopic dermatitis in children and their parents-a multicenter, randomized controlled trial. J Psychosom Res. 2010;68(4):353-8.

20. Weisshaar E, Diepgen TL, Bruckner T, Fartasch M, Kupfer J, Lob-Corzilius T, et al. Itch intensity evaluated in the German Atopic Dermatitis Intervention Study (GADIS): correlations with quality of life, coping behaviour and SCORAD severity in 823 children. Acta Derm Venereol. 2008;88(3):234-9.

21. Weber MB, Fontes Neto Pde T, Prati C, Soirefman M, Mazzotti NG, Barzenski B, et al. Improvement of pruritus and quality of life of children with atopic dermatitis and their families after joining support groups. J Eur Acad Dermatol Venereol. 2008;22(8):992-7.

22. Schut C, Mahmutovic V, Gieler U, Kupfer J. Patient education programs for childhood atopic dermatitis: who is interested? J Dtsch Dermatol Ges. 2012;10(9):657-61.

23.• Stalder JF, Bernier C, Ball A, De Raeve L, Gieler U, Deleuran M, et al. Therapeutic patient education in atopic dermatitis: worldwide experiences. Pediatr Dermatol. 2013;30(3):329-34.

International overview on experiences of educational programs in atopic dermatitis.

24. Dagregorio G, Guillet G. Educational seminars for adults with atopic dermatitis: preliminary report about 103 patients. Allergy. 2005;60(4):540-1.

25. Ehlers A, Stangier U, Gieler U. Treatment of atopic dermatitis: a comparison of psychological and dermatological approaches to relapse prevention. J Consult Clin Psychol. 1995;63(4):624-35.

26. Kernick D, Cox A, Powell R, Reinhold D, Sawkins J, Warin A. A cost consequence study of the impact of a dermatology-trained practice nurse on the quality of life of primary care patients with eczema and psoriasis. Br J Gen Pract. 2000;50(456):555-8.

27. Gradwell C, Thomas KS, English JS, Williams HC. A randomized controlled trial of nurse follow-up clinics: do they help patients and do they free up consultants' time? Br J Dermatol. 2002;147(3):513-7.

28. Coenraads PJ, Span L, Jaspers JP, Fidler V. Intensive patient education and treatment program for young adults with atopic eczema [in German]. Hautarzt. 2001;52(5):428-33.

29. Bostoen J, Bracke S, De Keyser S, Lambert J. An educational programme for patients with psoriasis and atopic dermatitis: a prospective randomized controlled trial. Br J Dermatol. 2012;167(5):1025-31.

30. Heratizadeh A, Werfel T, Gieler U. AGNES und ARNE-Konzept der Neurodermitisschulung für Erwachsene. Prävention Rehabil. 2011;23:41-2. [Abstract]. 